\title{
Study on Application of Financial Derivatives in Interest Rate Risk Management
}

\author{
Hongmei Zhang ${ }^{1}$ \\ Xi'an International University, 710077 \\ hunter2011@foxmail.com
}

Keywords: Interest Risk; Financial Derivatives; Management

\begin{abstract}
Since December 27, 2006, with the full liberalization of China's financial currency market, China's monetary policy influenced by international monetary policy has become increasingly large. Changes in interest rates and changes in the international interactive market interest rates have greatly increased. At the same time, China has also accelerated the process of marketization of interest rates, and thus, each of the market players, especially the interest rate risk faced by commercial banks will be greatly increased. Traditional methods for interest rate risk management on the assumptions due to the limitation of its operability and effectiveness had been greatly reduced. In order to effectively manage interest rate risk, it is necessary to study our country as an international financial market, mainly hedge derivative financial instruments used in interest rate risk management. This paper studies the characteristics of financial derivatives in interest rate risk management application, demonstrated the effectiveness of financial derivatives in interest rate risk management.
\end{abstract}

\section{Introduction}

Definition of risk is lower for people due to the uncertainty of the future behavior of decision-making and objective conditions, and leading to the degree of deviation of the actual results and expected results. Clearly, the fundamental reason is that the risk of Uncertainty. Because research different angles, defined as the difference between the interest rate risk also now more typical definition of two kinds. First, the Basel Committee on interest rate risk management principles published in 1997, the interest rates risk is defined as the bank's exposure to the financial situation interest rate changes. Second Song Fengming sets the interest rate risk. There are subtle differences between the two of Sichuan. The former emphasizes adverse fluctuations in interest rates financial risk under the premise of the bank, the latter is more emphasis unforeseen fluctuations in interest rates, but both illustrate the interest rate risk from changes in interest rates. Uncertainty mainly changes in interest rates the uncertainty of the time dimension on. such as: changes in economic forms, international changes in interest rates, exchange rate fluctuations and other international further, according to research old gold, interest rate risk can be broken down into periodic risk and Perseverance Risk periodic risk refers to the initial interest rate deregulation, commercial banks can not meet the market interest rate environment generated financial risk, interest rate risk is the market transition period, systematic and phased;. Permanence risk that is. Interest Rate Risk Management Theory of Western interest is commonly referred to, and different stages of risk, long-lasting. risk from changes in market interest rates uncertainty, business assets and liabilities of commercial banks is inherent interest rate risk, long-term and non- Systemic Just implement market-oriented interest rate, it must be accompanied by long perseverance risk, the size of the commercial banks to withstand this kind of interest rate risk depends on the level of its risk management .. Interest rate risk is defined herein: due to unexpected changes in market interest rates leaving the income may change. risk on the progress of China's current interest rate market, the current China's interest rate risk is mainly stage risk. Interest rate risk management is most suitable for banks, non-bank financial institutions and a large number of borrowers or corporate investments. Industry article from the perspective of commercial banks to discuss the management of interest rate risk, but many management methods and Tool also applies to non-bank institutions. 
The rise and development of financial derivatives is the rapid diffusion and widespread application of one of the most prominent changes in financial derivatives nearly 30 years of international financial markets, the new round of financial innovation since the 1970s pushed ask climax. With the accelerated process of global economic integration, cross-border operations of financial machines institutional investors and businesses generate avoid market risks, hedging strong demand, an urgent need to be able to avoid the risk of tool types. In order to meet market demand, financial institutions started to develop and to provide various types of financial derivatives market competition.

With economic globalization, an increasingly wide range of financial liberalization in China has such a huge market, and a large domestic market and uneven development, and how to learn, learn, learn and use financial derivatives to meet the international financial markets challenges become imminent, witch problem to be solved. In this context, study of the financial derivatives market interest rate risk management, the process of China's interest rate market interest rate risk management in the forward-looking but also has some great practical significance.

\section{Interest Rate Risk Concept and Its Reasons}

The Concept of Interest Rate Risk. Due to the different angles of research, defined as the difference between the interest rate risk also. Currently there are two more typical definition. First, the Basel Committee published in 1997, "interest rate risk management principles", the interest rate risk is defined as the financial situation of the bank's exposure to interest rate changes. Second, the interest rate risk is the risk Song Fengming defined as the unforeseen changes in interest rates leaving income may change. There are subtle differences between the two, the former is emphasized in the context of unfavorable interest rate fluctuations in the bank's financial risk, the latter is more emphasis unforeseen fluctuations in interest rates. But both illustrate the interest rate risk from the uncertainty of changes in interest rates. The uncertainty of changes in interest rates is mainly for the uncertainty on the time dimension. Such as: economic forms change, international changes in interest rates, exchange rate fluctuations and other international. Further, according to research old gold, interest rate risk can be broken down into periodic risk and permanent risk. Interest rate risk is defined herein: the risk of accidents due to changes in market interest rates leaving income may change. On the process of marketization of interest rates for now, China's current interest rate risk is the stage risk.

Cause of Interest Rate Risk. Interest rate risk refers to the period of time, the situation returned to normal loan principal and interest, the possibility of leaving due to market fluctuations in interest rates of commercial banks to reduce or increase the profit loss. He stressed the interest rate under the premise of adverse fluctuations in financial risk, interest rate risk from changes in interest rates the bank uncertainty. Cause of interest rate risk may simply be attributed to two aspects: external and internal factors. External factors include the evolution of the economic situation changes, the transition macroeconomic policies, financial market volatility, changes in international interest rates, international currency fluctuations of the domestic political situation, these macroeconomic factors will affect the market trend of interest rates, and ultimately to commercial banks have a positive or negative impact. Internal factors include the asset-liability structure; weak awareness of interest rate risk; interest rate decision management mistakes; human error operator; unreasonable internal management mechanism; technology and backward technology and other means, these micro factors that affect interest rate risk internal reasons.

Since the interest rate risk is mainly affected by unexpected changes in interest rates and interest rate risk exposure, and to eliminate or reduce interest rate risk exposure is mainly because we can not accurately predict changes in interest rates, which is a forced interest rate risk management tool. If It means future trends can more accurately determine the price of money) interest rates, then we can thus measure interest rate risk, take the initiative to adjust discretionary assets and liabilities. In fact, the positive interest rate risk management approach must be based on the correct interest rate forecast on the basis of, or can only expand the interest rate risk they assume. Changes in interest rates are to a single market participants can not control and impact, that yes, right in terms of 
individual economic entities, changes in interest rates is uncertain. The second is Uncertainty relative information. mathematical principles of the founder of information theory Shannon brilliant writings communicating proposed: definition information for/to eliminate the role of uncertainty thing is to eliminate the uncertainty of information is uncertain negative information measure, increased information means reducing uncertainty and therefore deal with uncertainty How to grasp the problem becomes even more information.

Currently, financial derivatives gained considerable development, which in addition to objective economic environment thanks to need outside, but also by its own peculiar features of the decision, specifically, financial derivatives has the following main functions: (l)To avoid risks, hedging; (2) The role of price discovery; (3) To increase market liquidity; (4) Reduce financing costs; (5) Asset liability Management

\section{Financial Derivatives Application in Interest Rate Risk Management}

Price Discovery of Financial Derivatives Used in Interest Rate Risk Management. In a market economy, the price is the most basic and most important information. The forecast for interest rates is to try to find an asset or liability changes in future price trends for the balance gap, adjust the proportion of assets and liabilities in advance, in order to eliminate or reduce the risk of changes in interest rates brought about. Financial derivatives transactions in the spot on the basis of the results generated by assets possible future transactions. Its transaction and the results should come to the end of time in order to produce a convention on the spot. Financial derivatives market approximate perfectly competitive market. Thus, the price of financial derivatives are formed both to improve the transparency of information and to make the price close to the supply and demand equilibrium price therefore, financial derivatives, the price formation Ding field often become national, county to prices worldwide. Los price information sources in this market to provide market participants can make a more accurate grasp of the market, of course, commercial banks are the main actors and users.

Estimates of market expectations for a long time by the primary financial instruments to observe. However, through the financial derivatives market study to obtain market expected to be superior than more traditional methods. Proactive interest rate risk management approach must be based on the correct prediction based on interest rates, or only widen the interest rate risk they assume.

Financial Derivatives Used in Hedging the Interest Rate Risk Management. Since the accuracy deviation and commercial bank balance sheet structure prediction rate adjustment limitations, if the interest rate trend forecast full rely on and adjust the structure of assets and liabilities of commercial banks to avoid interest rate risk is unrealistic, therefore, banks also need to seek tools to avoid interest rate risk, and financial derivatives hedging function has become the most important moment of choice. When a combination of price changes affect risk factors changed, after the value of the portfolio hedging unchanged. The basic functions of financial derivatives are hedging. Derivatives can be included in the base price of risk assets partially decomposed, separate pricing and trading, which allows the user to limit the exposure to be tailored to their own preferences and the economic risk of their own, carry out the transfer of price risk and redistribution. The use of derivatives to hedge is the use of futures, forward agreements, swaps and other financial derivatives, held with the spot size of the market position considerably, opposite position, in order to eliminate price risk hedging a net position risk management methods. The option can eliminate adverse change in beneficial changes reserved.

\section{Conclusion}

China's commercial banks face a huge interest rate risk. After a variety of interest rate risk management of banks empirical analysis has been conducted, it is found that asset-liability ratio was significantly higher in joint-stock commercial banks, the capital adequacy ratio of most banks in the listing standards, interest rate sensitivity of a few banks and interest rates contrary to expectations. According to the characteristics of the various interest rate derivatives, the paper 
believes it can reasonably be expected in the case of interest rates, you can use interest rate futures contracts and forward contracts to lock in future interest rates and future borrowing costs: the use of interest rate options to protect bond portfolio; commercial banks use interest rate swaps to change the interest rate fluctuation risk exposure and make access to lower borrowing costs.

\section{References}

[1] F.M. Song. Modern Commercial Bank Management. Tsinghua University Press. 1996, pp242-250.

[2] L. Zhou. Interest Rate of Commercial Bank Risk Control, Economic Research. 2001.1.

[3] Elijah Brewer, William E.Jakson and Jmaes T. Moseer. The Value of Using Interest Rate Derivatives to Mange Risk at U.S. Banking Organizations. Federal Reserve Bank of Chieago, Vol:30,2001.

[4] Magali Vanbelle. Tow Essays on The Use of Interest Rate Swaps.MUI Dissertation Services, Decemeber,1999. 